Katerina Plaksiy

Kyiv National University of Technologies and Design (Kyiv)

Scientific supervisor - Tuhaienko V.M.

\title{
GLOBAL ENVIRONMENTAL PROBLEMS
}

Scientific and technological progress posed a series of new, very complex problems for mankind, which it had not encountered before, or they were not so large-scale. Among them, a special place is occupied by the relationship between man and nature. Scientists claim that from about the 1960s and 70s, environmental changes under the influence of humans became global. Among them, the most relevant:

-Earth's climate change, global warming;

-air pollution;

-destruction of the ozone layer;

-pollution of the oceans;

-land pollution, soil cover destruction;

-impoverishment of biological diversity, extermination of animal species, plant varieties.

Let's consider everything in order:

Global warming is dragging drastic and unpredictable climate changes and this is the result of human activity - we are talking about greenhouse gas emissions. Global warming leads to an increase in the temperature of the oceans and the earth's surface, causing the melting of polar ice, rising sea levels, as well as unnatural weather conditions that lead to flooding, blizzards or, conversely, desertification. This is also bad for farms: fields and farms, because warming is decreasing due to warming.

Pollution makes air, water and soil unsuitable. It takes millions of years to neutralize the effects of these contaminants. Industry and car exhaust are the main 
source of substances that pollute the air. Gases and toxins released by industrial enterprises result from fuel combustion. Most often, industrial enterprises exceed a coefficient that should not exceed 1.5. In such cases, they must pay a fine (at least one), but the directors have learned to circumvent the laws, so they indicate false values.

The destruction of the ozone layer increases the number of diseases. Depletion of the ozone layer is explained by pollution caused by chlorine and bromides found in chlorofluorocarbons. They are banned in many industries and consumer products. After these toxic gases reach the upper atmosphere, they "eat" a hole in the ozone layer - the largest of them is above the Antarctic. As a result of the destruction of the ozone layer, ultraviolet radiation passes unhindered through the atmosphere and reaches the surface of the earth. Exposure to direct ultraviolet rays adversely affects people's health, weakening the immune system and causing diseases such as skin cancer and cataracts, and also affects plant life and the reduction of plankton in the marine environment.

Water pollution often occurs due to oil spills, acid rain, and urban sewage. While industry dumps toxic substances into rivers and oceans, water becomes an economic and political issue, people are fighting for this resource. One way to get usable water is to desalinate it.

Chemical waste is dumped into the ocean, causing animals, fish and plankton to die, the surface of large areas covered with oil film, and non-decomposable synthetic waste turned into garbage islands. In short - this is not just pollution, but a real disaster.

Now people are trying to somehow fix this by clearing the water of all discharges and oil spills or even building entire cities on garbage islands, although the latter does not really solve the problem. This is just rational use, but this solution cannot change the situation. 
Land pollution is mainly caused by industrial waste, depriving the soil of essential nutrients. The main role in soil pollution is played by such components of industrial waste as heavy metals (lead, mercury, cadmium, arsenic, thallium, bismuth, tin, vanadium, antimony), pesticides and oil products. From the soil they penetrate into plants and water, even spring water. On a chain toxic metals enter the human body and are not always quickly and completely eliminated from it. Some of them tend to accumulate over many years, provoking the development of serious diseases.

Loss of biodiversity - destruction of ecosystems and extinction of species.

Ecosystems that took millions of years to achieve perfect balance are at risk when a population of a species falls. The balance of natural processes, such as pollination, critically affects the survival of the ecosystem. And human activity puts him at risk. Another example is the destruction of coral reefs that support rich marine life.

Damage in this area is already quite noticeable. This is due to the destruction of the habitat of plants and animals, excessive exploitation of agricultural resources, environmental pollution. According to American scientists, over 900 thousand species of plants and animals have disappeared on Earth over the past 200 years. In the second half of the XX century. the process of reducing the gene pool has accelerated sharply, and while maintaining current trends over the past quarter century, the disappearance of $1 / 5$ of all species that inhabit our planet today.

First of all, you need to find like-minded people who are not indifferent to what is happening around, together with them, determine what problems exist in your area, and select from them those that need to be addressed in the first place. You also need to identify residents whose interests are affected by activities carried out in your territory. When you have decided on the problems and participants, try to imagine the image of the desired future of your area: how you see your city, street, courtyard, what changes you would like to bring to its life. When you will clearly understand what and how you are going to change, you can begin to plan, and then to implement 
specific actions. And what is very important, on this path it is necessary to be able to evaluate the results of your activities.

My suggestions on how we can prevent these situations from getting worse:

$\checkmark \quad$ Firstly, the consumption of energy and water resources. Saving this consumption will help save the planet's resources.

$\checkmark \quad$ Secondly, the presence of a car. The more private cars, the more harmful emissions into the atmosphere and more pollution.

$\checkmark \quad$ Thirdly, the presence of pets. Uncontrolled breeding of domestic animals, the absence of natural selection among them, leads to the appearance of a large number of stray dogs and cats, thereby violating the ecological balance.

$\checkmark \quad$ Fourth, the culture of consumption. Currently, all purchased items are packaged. Most packages do not decompose naturally. Garbage is thrown away wherever necessary. To reduce the ecological footprint, it is necessary not only to monitor the release of garbage into specially designated places, but also to sort it, which will help to reduce the land area occupied by landfills, as well as the appearance of additional raw materials due to waste processing.

The environmental problem is one of the global problems of our time. It is closely linked to environmental safety and crisis issues. One of the ways to solve the environmental problem is the path of "sustainable development", proposed as the main alternative to the development of human civilization.

\section{REFERENCES}

1. Екологічна проблема людства [Електронний ресурс] - URL: https://obrazovaka.ru/geografiya/globalnye-ekologicheskie-problemychelovechestva.html

2. Екологічні проблеми [Електронний ресурс] - URL: https://lingvana.ru/ecological-problems.html 